\title{
AÇÕES EDUCATIVAS PARA REDUÇÃO DA ANSIEDADE DA CRIANÇA SUBMETIDA À CIRURGIA CARDÍACA E SUAFAMÍLIA
}

\section{Pôster}

Autores deste trabalho:

Rosa Ines Etchichury Rolim: Hospital Moinhos de Vento

Sabrina Dau Vendrame: Hospital Moinhos de Vento

Jeniffer Lorenzi: Hospital Moinhos de Vento

Área do Trabalho: Enfermagem pediátrica

Data da submissão:10/08/2018 às 16:52

\section{Justificativa}

A internação hospitalar para a criança e seus familiares traduz uma experiência muito difícil, gerando ansiedade pela exposição da criança a um ambiente estressante. A hospitalização é percebida como ameaçadora, tendo um impacto sobre o comportamento da criança, levando à manifestação de reações adversas como o estresse, ansiedade e medo. A necessidade de ser submetido a procedimentos invasivos como as cirurgias potencializam estas reações. A preparação pré cirúrgica é extremamente importante, pois aproxima a equipe de enfermagem, estabelece uma relação de confiança, facilitando o atendimento e possibilitando certo grau de controle da criança e da família sobre o desconhecido.

\section{Objetivo(s)}

Descrever as intervenções educativas pré cirúrgicas realizadas pelas enfermeiras assistenciais com crianças portadoras de cardiopatia congênita e sua família, denominada "Visita do Coração", em uma instituição de saúde privada de grande porte, na cidade de Porto Alegre/RS.

\section{Método(s)}

Realizada simulação realística dentro da Unidade de Terapia Intensiva Pediátrica, onde os pais e a criança puderam conheceram a equipe assistencial, estrutura física, equipamentos para monitorização da criança e dispositivos médicos necessários para o atendimento no pós operatório imediato. A criança pôde manipular os equipamentos e dispositivos adaptados a um boneco e questionar a finalidade dos mesmos.

\section{Resultado(s)}

É indiscutível o valor da preparação da família e da criança submetida a procedimentos cirúrgicos. As informações devem ser simples, realísticas e verdadeiras.

\section{Conclusão (ões)}

Os desfechos obtidos em pacientes e pais preparados para a cirurgia consistem em sofrer menos com ansiedade, se portar de forma mais positiva e colaborativa, contribuindo assim para o sucesso da recuperação da criança. 